\title{
CAMPO DE ÁCIDO: UMA ALTERNATIVA PARA O ENSINO DAS FUNÇÕES
}

\author{
ÁCIDO E BASE
}

\author{
Ionara Aquino Rios ${ }^{1}$; Maria de Fátima Mendes Paixão²; Emilly Adorno de Lima \\ Vasconcelos ${ }^{3}$. \\ 1. Bolsista PROBIC/UEFS, Graduanda em Licenciatura em Química, Universidade Estadual de Feira de Santana, \\ yonararios2007@hotmail.com \\ 2. Orientadora, Departamento de Ciências Exatas, Universidade Estadual de Feira de Santana, \\ fpaixao100@gmail.com \\ 3.Participante do projeto, Graduanda em Engenharia de Alimentos, Universidade Estadual de Feira de Santana, \\ millyadorno95@gmail.com
}

PALAVRAS-CHAVE: Jogos, Educação Química, Antocianinas

\section{INTRODUÇÃO}

Entre os desafios presentes na docência, acredito ser o maior deles, o de contribuir para a aprendizagem, quando o desejo do educador é favorecer a que seus estudantes adquiram um conhecimento significativo tenham uma compreensão mais próxima dos fenômenos que acontecem ao seu redor.

De acordo com os Parâmetros Curriculares Nacionais (PCN/1999) e enquanto componente curricular do ensino básico, a Química deve oferecer ao aluno a possibilidade de compreender os fenômenos abordados bem como de realizar sua avaliação, considerando o que apresenta a tradição cultural e a mídia, tornando-o cidadãos capacitados a refletir, construir opiniões e atuar no meio em que vive.

A Educação Química é compreendida como uma área da Química, embora se distinga das demais áreas desta ciência (química orgânica, físico-química etc.) não só pelo seu objeto de estudo e de investigação, mas também pelo pouco tempo de constituição como área (PCN,1999).

No que se refere ao ensino de ciências, uma ferramenta que vem auxiliando os professores a transformar a sala de aula em um local mais dinâmico e participativo, sobretudo no ensino de Química, é a experimentação. Contudo, outras ferramentas didáticas também podem dar esse suporte ao professor, que insatisfeito com a metodologia tradicional de ensino busca formas para envolver os alunos na aprendizagem da ciência supracitada. Podemos citar o teatro, a música, a modelagem, os jogos, entre outros. Segundo Cunha (2012), os jogos didáticos vêm sendo utilizados para direcionar o ensino de conceitos, pois o fato de possuir regras que equilibram o lúdico e a função educativa, os jogos favorecem ao aprendizado do conteúdo e contribuem para a formação do sujeito. Associado a isso, o uso de jogos permite a vivencia de valores morais importantes para a formação do educando, tais como a cooperação, a realização de trabalhos em grupo, o saber perder e ganhar na realização das tarefas da vida (BROTTO, 2001).

Segundo Soares (2012) os desafios e obstáculos que os jogos apresentam, despertam no aluno a curiosidade e o interesse, podendo assim ser utilizado em sala de aula com a finalidade de estimular a busca do conhecimento. Neste contexto, foi elaborado e aplicado em aula de Química de alunas da segunda serie de uma escola pública da cidade de Feira de Santana, o jogo "Campo de Ácido", utilizando antocianinas, pigmentos que podem ser usados como indicadores naturais de ácido e 
base, visando contribuir de forma lúdica e motivadora para aprendizagem do tema acidez basicidade.

\section{METODOLOGIA}

\section{Preparação Inicial}

Foram feitos testes com flores existentes no campus da UEFS (Universidade Estadual de Feira de Santana), que possuíam coloração entre o vermelho e o roxo, para extração do pigmento da antocianina. Os extratos foram preparados através de maceração com almofariz e pistilo, usando como solvente álcool e água, a frio, em uma proporção de 1:1 para a água e 1:1/2 para o álcool, neste caso, uma mistura de solventes. Para identificação da cor em meio ácido e básico foram feitos testes com soluções de ácido clorídrico ( $\mathrm{HCl}$ 0,10 mol/L) e hidróxido de sódio $(\mathrm{NaOH} \mathrm{0,10} \mathrm{mol} / \mathrm{L})$. Além disso, foram testados vários tipos de papeis que pudessem ser usados para o preparo do jogo, visando encontrar aquele cujo resultado fosse satisfatório quanto a visualização das cores nas cartelas do jogo.

\section{Elaboração do jogo: Montagem do campo ácido}

A elaboração do jogo tem como referência o conhecido jogo "Campo Minado". O papel de filtro foi cortado em cartelas e 25 quadrados foram desenhados com lápis preto grafite e régua. Seis quadrados foram pintados com a solução de $\mathrm{HCl}$, a livre escolha, utilizando hastes flexíveis, criando assim um meio ácido no papel em seis quadrados, que serão como as bombas do tradicional Campo Minado. Após secar o papel, foram feitas as marcações com bolinhas utilizando a solução de $\mathrm{NaOH}$ e um palito. Essas marcações foram feitas em quadrados próximos aos usados como bomba (quadrado ácido) e indicam as possibilidades de campos ácidos nas imediações daquele quadrado.

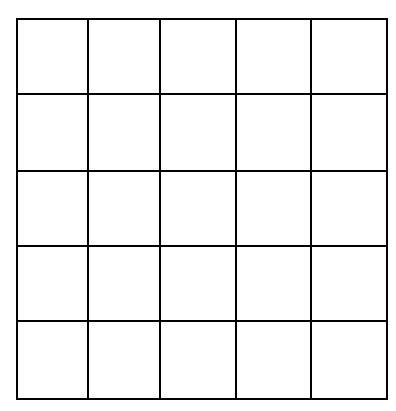

Tabela 1: Tabela quadriculada preparada para o jogo.

\begin{tabular}{|l|l|l|l|l|}
\hline $\mathrm{A}$ & 1 & 1 & $\mathrm{~A}$ & 1 \\
\hline 1 & 2 & 2 & 3 & 2 \\
\hline 0 & 1 & $\mathrm{~A}$ & 2 & $\mathrm{~A}$ \\
\hline 1 & 3 & 3 & 3 & 1 \\
\hline 1 & $\mathrm{~A}$ & $\mathrm{~A}$ & 1 & 0 \\
\hline
\end{tabular}

Tabela 2: Representação das indicações de campos ácidos.

A tabela 2 acima sugere uma das muitas possibilidades de tabela completa, onde os quadros que estão preenchidos com a letra A representam aqueles que foram pintados com ácido. Ao seu redor (indicado por números na tabela 2) aparecem as possibilidades de quadros com a quantidade de bolinhas feitas com palito e uma solução básica, indicando o número de bombas nas proximidades daquele quadrado. Após secagem, todo material possui aparência incolor, similar à apresentada na tabela 1. Após preparados, os papeis foram postos para secar. Na sequência, foi feito o teste piloto do jogo, seguindo as regras propostas e apresentadas a seguir. 


\section{Regras do Campo Ácido}

1. O primeiro participante da dupla pintará (com um pincel fino) apenas um quadrinho, utilizando o extrato de antocianinas. Na sequência será a vez do seu parceiro, que deverá repetir a ação anteriormente citada para outro quadrinho, observando a resposta obtida pelo seu colega.

2. Ao usar o extrato, quem encontrar um campo ácido passa a vez.

3. O jogo acaba quando todos os campos ácidos forem encontrados.

4. Vence quem encontrar menor quantidade de campos ácidos.

\section{Aplicação do Jogo em sala de aula}

Inicialmente foi feito um diagnóstico do conhecimento da turma quanto ao tema acidez basicidade, referente ao conteúdo Funções da Química Inorgânica, através de questionamentos que relacionem esse conteúdo com o cotidiano. Em seguida, foi apresentada a proposta de elaboração do jogo, utilizando extratos de antocianinas. Nesse momento, através de sondagem em uma roda de conversas, foram solicitadas contribuições dos estudantes, de acordo com seus conhecimentos prévios relativos ao assunto e às suas afinidades com jogos, buscando entender se eles têm conhecimento sobre o jogo proposto para este trabalho.

A etapa seguinte foi a realização do jogo em sala de aula. A turma foi dividida em duplas e cada dupla recebeu uma cartela, duas hastes flexíveis e um copinho descartável de café contendo o extrato. Em seguida, foram apresentadas as regras do jogo. Após a aplicação, uma discussão foi aberta sobre a contribuição dada pela ferramenta educativa para o aprendizado do assunto. Os alunos tiveram a oportunidade de fazer suas colocações a respeito da relação do jogo com as funções ácido e base. Com o intuito de avaliar se os objetivos propostos foram alcançados, os alunos responderam um questionário.

\section{RESULTADOS E DISCUSSÃO}

A metodologia descrita foi definida com base nos resultados da pesquisa durante a construção do jogo. O papel, as soluções, o extrato de antocianinas e a forma como cada elemento seria utilizado foi definido a partir de testes em laboratório e da aplicação piloto do jogo com os colegas do curso de licenciatura em Química que já conheciam o jogo Campo Minado.

As cartelas foram confeccionadas no laboratório cerca de 10 hs antes da execução da aula, pois a coloração nos quadrados umedecidos com ácidos vai ficando difícil de visualizar depois desse intervalo de tempo e com o isso o jogo perde parte da sua funcionalidade.

Ao apresentar o jogo, os alunos se mostraram muito animados e toda a turma participou com muita atenção. Ao analisar o questionário, percebemos que $77 \%$ dos alunos já conheciam o jogo Campo Minado. A respeito do nível de dificuldade do jogo 
Campo de Ácido temos que 7\% do estudantes classificaram o jogo como difícil, $70 \%$ como mediano e $23 \%$ acharam o jogo fácil.

Quanto ao interesse despertado nos alunos para reproduzir o jogo, 94\% afirmaram que sim. Quando perguntados quanto a capacidade de relacionar o jogo com o conteúdo abordado, $100 \%$ afirmaram que o jogo ajudou no aprendizado das reações ácido-base e que haviam gostado desse tipo de aula.

Foi perceptível que o jogo Campo de Ácido contribuiu de forma positiva para o processo de aprendizagem das reações ácido-base, deixando a aula de Química mais atrativa e dinâmica. A escola em que foi ministrada a aula não tem laboratório e aulas com atividades voltadas para a experimentação provocam entusiasmo e estimulam a curiosidade dos alunos, propiciando discussões e reflexões que contribuem para o desenvolvimento da aprendizagem, bem como para aquisição de conhecimentos.

\section{CONSIDERAÇÕES FINAIS}

Apesar de usarmos $\mathrm{HCl}$ e $\mathrm{NaOH}$ em baixas concentrações na construção do jogo e evitar o contato dos alunos com essas soluções, acreditamos que o jogo deve ser elaborado com soluções ácidas e básicas mais comum em nosso dia a dia e que não ofereçam nenhum tipo de risco ao manuseá-las. Alguns testes foram feitos no laboratório, porém os resultados encontrados para o vinagre e o suco de limão não foram satisfatórios devido a rápida mudança da coloração. Já para a solução básica, o desengordurante utilizado durante os testes apresentou um ótimo resultado, contudo, avaliamos que não seria favorável utilizá-lo, optando pelo ácido clorídrico e pelo hidróxido de sódio bastante diluídos, soluções preparadas no laboratório.

\section{REFERÊNCIAS}

BRASIL. MEC. SEF. Parâmetros Curriculares Nacionais do Ensino Médio. Brasília, 1997.

BROTTO, F. O. Jogos Cooperativos: O jogo e o esporte como um exercício de convivência. Santos: Projeto Cooperação, 2001.

CUNHA, M. B. Jogos no Ensino de Química: Considerações Teóricas para sua Utilização em Sala de Aula. Química Nova na Escola, v. 34, n. 2, p. 92-98, maio de 2012.

SOARES, M. H. F. B. O Lúdico em Química: jogos e atividades aplicados ao ensino de Química. São Carlos: UFSCar, 2012. 